\title{
Genetically Engineered Antifungal Wheat has no Detrimental Effects on the Key Soil Species Lumbricus terrestris
}

\author{
Andreas Lindfeld and Wolfgang Nentwig*
}

Institute of Ecology and Evolution, University of Bern, Baltzerstrasse 6, CH-3012 Bern, Switzerland

\begin{abstract}
Since the first introduction of genetically engineered (GE) plants, one of the major concerns has been their potential effects on non-target organisms and ecosystem services. We focused in this study on the earthworm species Lumbricus terrestris as important ecosystem engineer and studied its performance when feeding on GE antifungal wheat. We compared litter consumption, weight change and mortality of individuals feeding on GE wheat with either specific resistance against powdery mildew (Blumeria graminis) or unspecific resistance against fungi via chitinase and glucanase expression with individuals feeding on non-GE wheat or other conventional crops. We did not find detrimental direct or indirect effects of GE wheat on L. terrestris and overall L. terrrestris tended to cope even better with GE wheat varieties. Concluding from our experiment the transgene products do not harm the soil key species L. terrestris and ecosystem services like decomposition, organic matter turnover and nutrient cycling are unlikely to be affected detrimentally.
\end{abstract}

Keywords: Annelids, decomposition, lumbricids, genetically engineered, wheat, antifungal.

\section{INTRODUCTION}

The use of genetically engineered (GE) plants increased considerably during the last fifteen years. Starting 1996 with six countries cultivating GE plants, today 25 countries grow biotech crops commercially, covering an area of 134 million ha in 2009 (James, 2009). The development in cultivation of GE crops from 1996 to now reveals that the commercial cultivation of GE crops will probably further increase over the coming years (Sanvido et al., 2007). Genetic engineering is, beside potential benefits like more agricultural output or less pesticide use, accompanied by concerns about potential detrimental effects on the environment. GE plants will possibly change ecological interactions and ecosystem services such as decomposition since they will eventually be grown under field conditions (Mulder and Lotz, 2009). Hence it is essential to do ecological risk assessments (ERA) prior to the release of GE plants and assess all effects on their surrounding environment and evaluate whether ecosystem services and functioning are affected. The impact on non-target organisms is one of the major concerns about genetically engineered plants (Sanvido et al., 2007).

The soil is a resource of water, nutrients and minerals which are essential for primary producers. Soil flora and fauna provide many ecosystem services like organic matter decomposition, nutrient mineralisation and immobilisation, reduction-oxidation reactions, and nitrogen fixation and solubilisation (Brussaard et al., 1997; Wardle 2002). Furthermore there is a complex building of interactions between soil organisms affecting each other, e.g. soil fauna maintains and shapes microbial activity (Moore et al., 1988). Larger soil dwelling fauna has vital effects on improvement and

*Address correspondence to this author at the Institute of Ecology and Evolution, University of Bern, Baltzerstrasse 6, CH-3012 Bern, Switzerland; Tel: ++41 31631 4520; E-mail: wolfgang.nentwig@iee.unibe.ch maintenance of soil structure and hence gas exchange and soil hydrology (Brussaard, 1998; Wardle, 2002; Lavelle et al., 2006). Especially earthworms take a key role in these processes (Scheu, 2003; Brown and Doube, 2004). They influence soil habitat properties and the availability of resources for other organisms (animals, microorganisms, plants). In temperate regions, earthworms are considered to be the most important group of soil invertebrates (Dunger and Fiedler, 1997) and are regarded as ecosystem engineers (Jouquet et al., 2006). If GE plants affect earthworms performance in some way this might affect the ecosystem services they provide. Furthermore other soil organisms interacting with earthworms might be affected. Modification, limitation or even loss of ecosystem services and functioning are potential consequences (Tan et al., 2010). Ecological risk assessments (ERA) of GE plants involves generating, collecting and assessing information on a GE plant in order to determine its potential adverse impact relative to its nonGE plant comparator, and thus assessing its comparative safety (EFSA, 2010). Due to their central role in soil ecosystems the integration of earthworms in such ERA's of GE plants is indispensable.

Studies about several soil fauna taxa have been donen in case of Bt crops, e.g. enchytraeids (Hönemann et al., 2009) or dipteran larvae (Knecht et al., 2010). Several studies have been done investigating potential effects of $\mathrm{Bt}$ crops on earthworms (Saxena and Stotzky, 2001b; Zwahlen et al., 2003; Liu et al., 2009; Zeilinger et al., 2010) but little research has been conducted about effects of fungicidal GE wheat on soil fauna (Romeis et al., 2003; Peter et al., 2010; Lindfeld et al., 2010) and nothing so far about effects on earthworms.

We account for this lack of knowledge with this study and investigated the anecic earthworm species Lumbricus terrestris. L. terrestris is one of the most common earthworm species in Europe, ubiquitous in agricultural soils 
and is known to be an important ecosystem engineer (Brown and Doube, 2004). L. terrestris feeds mainly on leaves with roots as a minor component in its diet (Lee, 1985).

Effects on L. terrestris can either be direct via transgene products or indirect via pleiotropic effects. Indirect effects on $L$. terrestris are more probable since the transgenes produce no toxic substances, which aim on lumbricids. The randomly insertion of a transgene into the genome of a host plant may change plant metabolism via undesired effects on other host genes or their regulation, for example, resulting in an altered $\mathrm{C} / \mathrm{N}$ ratio, lignin content or secondary metabolite composition in the host plant (Ioset et al., 2007; Kulikov, 2005). These so-called pleiotropic effects possibly result in a change of the nutritional value and also change palatability and decomposability (Saxena and Stotzky, 2001a; Poerschmann et al., 2005). This might affect earthworm performance and consumption behaviour since easily degradable crop varieties form better food resources. As a consequence ecosystem services such as decomposition, organic matter turnover, nutrient cycling and perhaps even water saturation might be affected negatively. Our risk formulation in terms of an ERA is: GE wheat has detrimental effects on L. terrestris or changes its feeding activity. This might lead to modification, limitation or even loss of ecosystem services like decomposition, organic matter turnover and nutrient cycling.

We analysed in a laboratory feeding experiment if there are differences in the consumption of leaves of several GE wheat varieties and their corresponding isolines or genetic wild type background and compared this to differences among conventional wheat varieties as well as among different crop species. We hypothesised that if there are detrimental direct or indirect effects of GE wheat (a) there is a lower litter consumption of GE wheat compared to non-GE wheat, (b) negative effects on biomass of lumbricids can be found when feeding on GE wheat compared to non-GE wheat and (c) there is a higher mortality in earthworms feeding on GE wheat compared to non-GE wheat. In case of the Pm3b varieties we do not assume detrimental effects of the transgene expression since their products are specific against powdery mildew. Furthermore we do not consider the transgene products of the A9 and A13 GE plants to be a problem since they naturally occur in other conventional plants (barley) with which L. terrestris has already come into contact. But overexpression of the transgenes and higher doses of their products or indirect effects due to a changed plant metabolism caused by the insertion or activity of the transgene might affect earthworms feeding activity and performance. However, differences in composition of structural plant components, such as lignin, cellulose or carbon and nitrogen are naturally occurring, too. These differences are caused by a high variation within the gene pool of a given plant species (Fernie et al., 2006). Furthermore there are differences in composition of structural plant components among different plant species. Hence the integration of several conventional wheat varieties as well as different crop species into an ERA is essential to assess naturally occurring variance of ecological interactions and processes. Thus one obtains adequate comparators as a baseline to get evidence for the true ecological risk of GE wheat for the key species
L. terrestris and to assess the comparative safety of a GE plant.

\section{METHODS}

\section{Plants}

In total, ten different spring wheat varieties (Triticum aestivum) were offered as food source in this experiment, with four of them being transgenic. We used two GE wheat varieties with a race specific resistance against powdery mildew (Pm3b1 and Pm3b2) as well as their corresponding isolines ( $\mathrm{Sb} 1$ and $\mathrm{Sb} 2$ ) as a control for the GE varieties. They are all based on the genetic background of Bobwhite SH98 26 (Bobwhite SH 9826 in the following referred to as Bobwhite), the wild type of a Mexican spring wheat variety. Those isolines are true sister lines of the GE varieties, which were treated technically the same way as the GE varieties but do not contain the specific wheat derived antifungal resistance gene against powdery mildew in their genome. Furthermore we used two GE wheat varieties (A9 and A13) with a broad antifungal resistance and their genetic background Frisal, a Swiss spring wheat variety. A9 plants had been genetically modified in a way that they express chitinase. In addition to chitinase expression, A13 plants also include genes coding for glucanase. Chitinase and glucanase are defensive proteins that enzymatically break down chitin and glucan respectively, two widespread integral parts of the cell walls in fungi (Kotilainen et al., 2004; Sundaresha et al., 2010). The transgenes in A9 and A13 stem from barley plants. The used GE lines are experimental varieties and not suitable for commercialisation. For detailed information about resistance in the used transgenic crops see Bliffeld et al., 1999; Bieri et al., 2003; Yahiaoui et al., 2004; Srichumpa et al., 2005; Bent and Mackey, 2007 and Ferreira et al. 2007. To analyse the naturally occurring variation between wheat varieties, three additional non-transgenic commercialised wheat lines were investigated, namely Bobwhite, Rubli and Toronit, with the latter two being Swiss spring wheat varieties. Supplementary to this wheat varieties also one barley variety (Estana) and one triticale variety (Trado) were implemented in this experiment, summing up in a total of twelve different crop varieties.

All plant material was obtained from the 2009 harvest of the field experiment at Agroscope Reckenholz-Tänikon Research Station in Zurich-Reckenholz. Only senescent leaves were collected. After collection leaves were dried in ventilating drying chambers at $34-38{ }^{\circ} \mathrm{C}$ for 1 week before they were handled further.

\section{Animals}

We chose the lumbricids species L. terrestris, for the experiment. Individuals were purchased from a commercial supplier (Fishing Supply, Niklaus Wenger, Bern, Switzerland). They were stored at $15^{\circ} \mathrm{C}$ under experimental conditions in the same soil as for the main experiment for two weeks to allow acclimatisation. During this period all animals were fed with beech leaves to avoid adaption to a certain wheat variety. Before starting the experiment, earthworms were checked for their physiological status as 


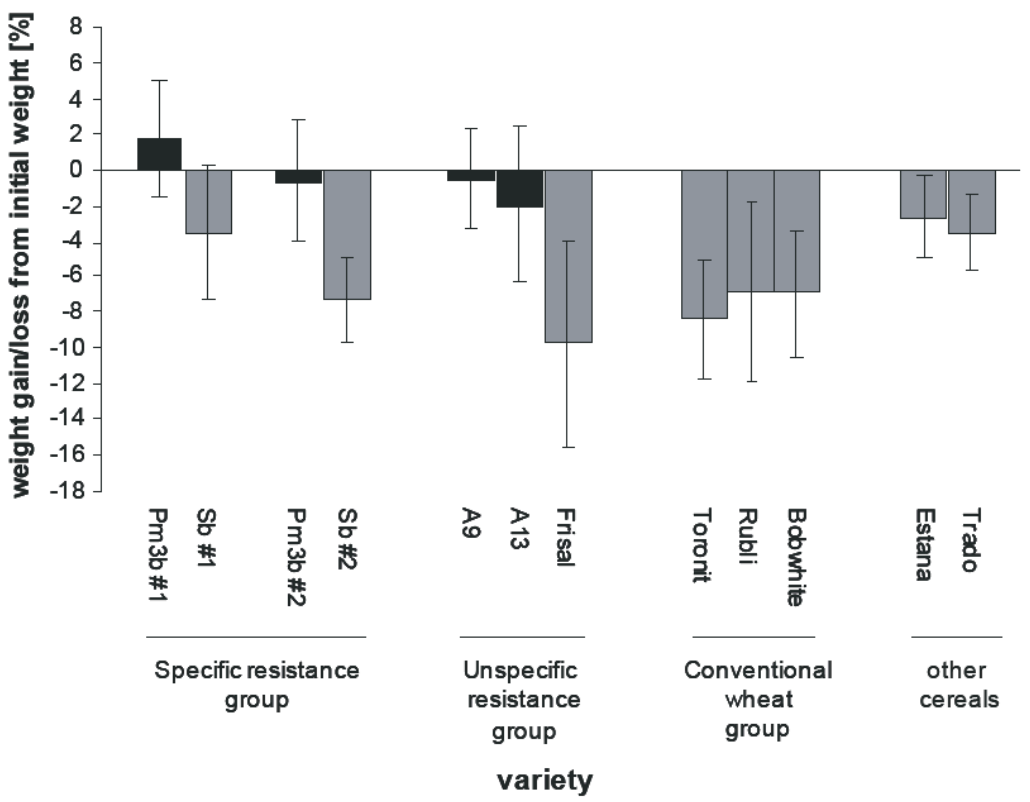

Fig. (1). Weight gain/loss in \% (mean \pm SE) of Lumbricus terrestris after 8 weeks when feeding on the GE (black) and non-GE (grey) crop varieties.

recommended by Fründ et al. (2010). Only active and healthy adults with a weight of about $5 \mathrm{~g}$ fresh weight were chosen.

\section{Experimental Setup}

The feeding experiment lasted 8 weeks and was conducted in a climate chamber under constant conditions with a temperature of $15^{\circ} \mathrm{C}$ and darkness. PVC cylinders with a height of $35 \mathrm{~cm}$ and a diameter of $11 \mathrm{~cm}$ were used for the laboratory trial. The bottoms of the PVC cylinders were sealed with plastic caps with small holes ( $2 \mathrm{~mm}$ diameter) for water drainage. Additionally $4 \mathrm{~cm}$ of a sand-grit mixture was placed on the bottom of the cylinders. Afterwards they were filled with $2 \mathrm{~kg}$ of commercial potting soil $(25 \%$ bark compost, $10 \%$ clay, $14 \%$ sand, $16 \%$ silt, $20 \%$ expanded clay, $15 \%$ wood fibre, $\mathrm{pH} 7.3)$. The water content of the soil was adjusted to field capacity. Adult $L$. terrestris were weighed prior to the experiment and one individual was placed into each cylinder. They were allowed to burrow into the soil before the leaf material was put onto the surface of the soil. $5 \mathrm{~g}$ dry weight of leaf litter pieces from $5-15 \mathrm{~cm}$ was placed in every PVC cylinder on top of the soil. Then cylinders were covered with fine mesh netting ( $2 \mathrm{~mm}$ mesh size) to allow for air circulation, but prevent lumbricids to escape. The cylinders were weighed separately and then placed randomly in the climate chamber. For each crop variety between 9 and 12 replicates were used depending on the available amount of leaf litter for the respective crop variety. In order to keep constant conditions, all cylinders were checked twice a week for weight loss due to leakage and water content was readjusted to field capacity if necessary. After eight weeks all remaining leaf litter was removed from the cylinders and washed from soil residues. All lumbricids were removed and weighed. Dead individuals were recorded after the experiment. Litter was dried for 7 days at $40^{\circ} \mathrm{C}$ and then weighed, too. The consumed leaf litter mass during the experiment was measured by subtracting the remaining litter residual mass from the initial litter mass. Results of the chemical analysis of hemicellulose, cellulose and lignin contents as well as the $\mathrm{C} / \mathrm{N}$ ratio of all crop varieties were taken from an earlier study by Lindfeld et al. (2010).

\section{Statistical Analysis}

The impact of genetic modification per se and the type of genetic modification were analysed with the data of the seven wheat varieties belonging to the specific and unspecific resistance groups (see Fig. 1). These seven varieties were classified into three pairs of varieties: two pairs belonging to the type of genetic modification "specific resistance", and one pair belonging to the type of genetic modification "unspecific resistance". Each of the two pairs of the specific resistance group consisted of one of the GE variety and the respective isoline. The only pair belonging to the unspecific resistance group consisted of the two GE varieties pooled (A9-Frisal and A13-Frisal) versus the wild type variety. We tested whether genetic modification and the type of genetic modification has an effect on the following dependent variables: litter consumption, lumbricids weight change and mortality. In order to correct for the individual lumbricid weight, the consumptions were put in relation to the fresh weight in grams of the respective lumbricid at the start of the experiment. For each dependent variable, a linear mixedeffects model with Gaussian error distribution was created. The fixed effects were type of resistance (two types: specific resistance to powdery mildew and unspecific resistance to pathogenic fungi, in the following referred to as "specific resistance" and "unspecific resistance") and transgenic (transgenic versus non transgenic). The random effects were the seven wheat varieties nested within the three pairs described above. To assess naturally occurring differences between the conventional wheat varieties, one-way ANOVA was calculated with the fixed effect variety (three factor levels: Toronit, Rubli and Bobwhite). To analyse differences between different crop species, one-way ANOVA was done 
with the factor crop species (three factor levels: wheat, barley and triticale). If necessary one-way ANOVA was followed by a Tukey HSD multiple comparison post hoc test. For all models residual analyses were conducted to check whether the model assumptions are fulfilled.

Differences in structural plant components and $\mathrm{C} / \mathrm{N}$ ratio were analysed with linear mixed effects models and one-way ANOVAs by Lindfeld et al. (2010). To check for pleiotropic effects we conducted a regression analysis of plant compounds and weight change or litter consumption, respectively. The computations were performed using $\mathrm{R}$ version 2.10.1 (R Development Core Team 2009). For regression analysis SPSS 17.0 for Windows was used.

\section{RESULTS}

\section{Earthworms}

Total mortality of earthworms was low with $4.2 \%$ (5 out of 120 individuals). Four of them fed on non-GE crops $(2 \mathrm{x}$ Toronit, Sb2, Trado) and one fed on a GE wheat variety (A13). There were no significant differences in mortality between GE and non-GE wheat ( $\mathrm{p}=1$; Fisher test).

The average fresh weight with gut content was $5.23 \pm$ $0.71 \mathrm{~g}$ at the start of the experiment. On average earthworms lost on all crop varieties weight during the experiment. Only when feeding on the GE wheat variety Pm3b1 we measured a weight gain of $1 \%$ of the initial weight. Overall weight loss was most in Frisal with about 10\%. Furthermore the earthworms lost about $7-8 \%$ of weight when feeding on the three conventional wheat varieties Bobwhite, Rubli and Toronit during the experiment (Fig. 1). The mean weight of L. terrestris varied about $6 \%$ between the $\mathrm{Pm} 3 \mathrm{~b}$ varieties and the $\mathrm{Sb}$ varieties, $9 \%$ between Frisal and $\mathrm{A} 9$ and $8 \%$ between Frisal and A13. Mean weight varied about 2\% among the other conventional wheat varieties Bobwhite, Rubli and Toronit. Differences among different crop species (wheat, barley and triticale) were about 5\%. However, earthworms weight loss was less when feeding on GE wheat varieties and they even gained weight in the case of Pm3b1, though this is not statistically significant. Statistical analysis revealed that neither the type of resistance (specific vs. unspecific) nor the presence of a transgene (GE vs. non-GE) did affect weight change significantly. A comparison of the three other conventional wheat varieties Bobwhite, Rubli and Toronit revealed no significant differences in mean weight change of L. terrestris among them. Furthermore there were no significant differences in weight change among crop species (wheat, barley, triticale) (Table 1).

Table 1. Plant Material Consumption in g per g Earthworm; Mean Values and Standard Error (SE) for the 12 Crop Varieties Used in this Experiment

\begin{tabular}{|c|c|c|}
\hline Variety & Consumed Plant Material & SE \\
\hline \hline Pm3b\#1 & 0.41 & 0.02 \\
\hline Sb\#1 & 0.55 & 0.03 \\
\hline Pm3b\#2 & 0.40 & 0.05 \\
\hline Sb\#2 & 0.50 & 0.03 \\
\hline A9-Frisal & 0.46 & 0.04 \\
\hline A13-Frisal & 0.55 & 0.06 \\
\hline Frisal & 0.47 & 0.02 \\
\hline Toronit & 0.52 & 0.03 \\
\hline Rubli & 0.54 & 0.03 \\
\hline Bobwhite & 0.54 & 0.04 \\
\hline Estana & 0.45 & 0.05 \\
\hline Trado & 0.48 & 0.03 \\
\hline Mean GE & 0.46 & 0.02 \\
\hline Mean non-GE & 0.51 & 0.01 \\
\hline Overall mean & 0.49 & 0.01 \\
\hline
\end{tabular}

\section{Litter Consumption}

During the experiment $0.49 \mathrm{~g}$ of leaf litter was consumed per $g$ earthworm fresh weight, averaged over all PVC

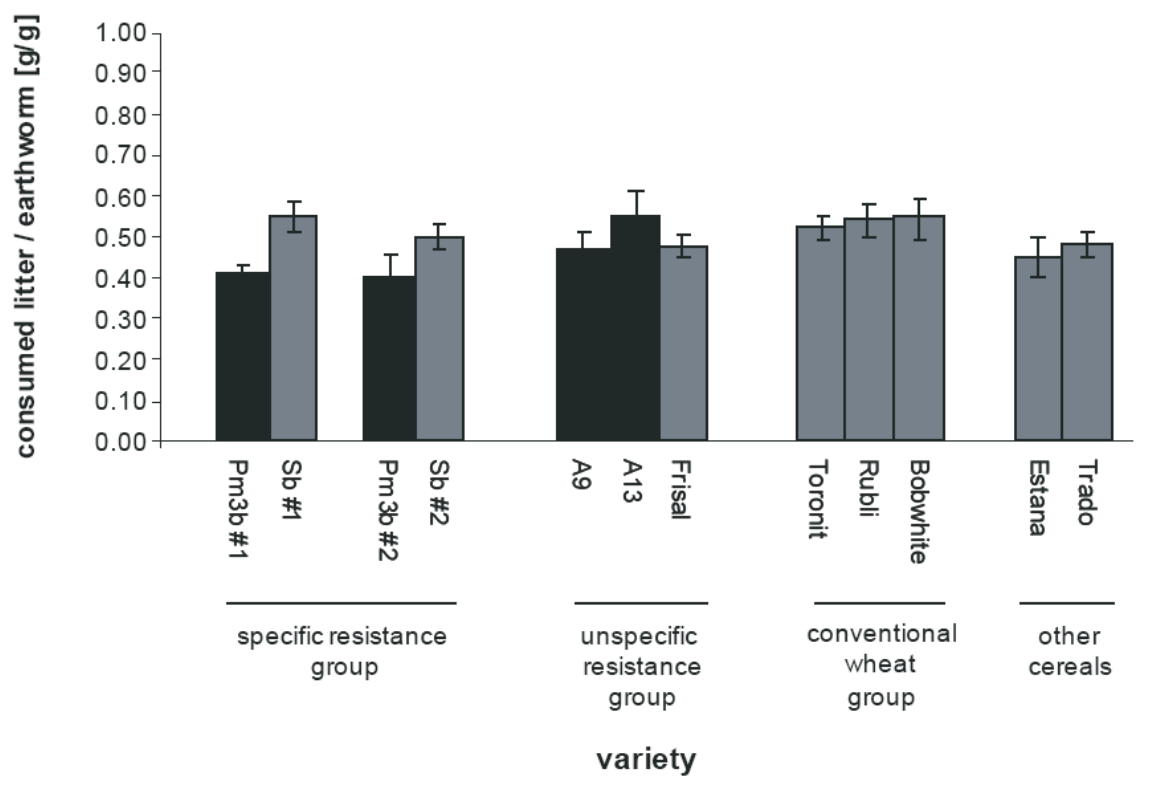

Fig. (2). Plant material consumption in g per g earthworm of the GE (black) and non-GE (grey) wheat varieties after 8 weeks. 
cylinders. Most litter was consumed in cylinders with the Sb1 and A13 varieties with about $0.55 \mathrm{~g}$ per $\mathrm{g}$ earthworm fresh weight. The GE wheat varieties Pm3b1 and Pm3b2 were consumed least. Most differences in consumed litter were between Pm3b1 and Sb1 with 25\% less consumed litter in the GE variety. The conventional wheat variety Frisal was consumed $13 \%$ less than its deriving GE variety A13 and 2\% more than A9. Among the three conventional wheat varieties Bobwhite, Rubli and Toronit differences were very small with $1 \%$. However, differences between different crop varieties (wheat, barley and triticale) were about $16 \%$ with wheat being consumed most and barley least (Fig. 2). Statistical analysis of the specific and unspecific resistance groups showed that neither the presence of a transgene (GE vs. nonGE) nor the type of resistance (specific vs. unspecific) did affect consumption significantly. Furthermore there were no significant differences in litter consumption among the conventional wheat varieties Bobwhite, Rubli and Toronit or among wheat, barley and triticale (Table 2).

Though there was a trend that consumption was negatively correlated with the weight gain of $L$. terrestris $\left(\mathrm{F}_{1,10}=\right.$ $4.272, \mathrm{p}=0.066$ ), regression analyses revealed no effect of lignin, cellulose, hemicellulose or the $\mathrm{C} / \mathrm{N}$ ratio on weight change or litter consumption of L. terrestris (Table $\mathbf{3}$ ). Results of the plant compound analysis are shown in Table 4.

Table 2. Results of the Weight Change and Consumption Analyses for the GE Group (LME, with Transgenic (Tr), Resistance Type (Rt) and their Interaction as Factors), the Conventional Crop Group and the Wheat Group (One-Way ANOVA, with Species Respectively Variety as Factor)

\begin{tabular}{|c|c|c|c|}
\hline & & $\begin{array}{l}\text { Weight } \\
\text { change }\end{array}$ & Consumption \\
\hline \multirow{9}{*}{ GE group } & $\begin{array}{l}\text { Transgenic } \\
\text { (Tr) }\end{array}$ & & \\
\hline & $F_{1,2}$ & 5.138 & 2.802 \\
\hline & $P$ & 0.152 & 0.236 \\
\hline & $\begin{array}{l}\text { Resistance } \\
\text { type (Rt) }\end{array}$ & & \\
\hline & $F_{1,1}$ & 0.953 & 1.453 \\
\hline & $P$ & 0.508 & 0.441 \\
\hline & $\operatorname{Tr} \times \mathrm{Rt}$ & & \\
\hline & $F_{1,2}$ & 0.177 & 0.490 \\
\hline & $P$ & 0.715 & 0.157 \\
\hline \multirow{3}{*}{$\begin{array}{c}\text { Conventional crop } \\
\text { group }\end{array}$} & Species & & \\
\hline & $F_{2,44}$ & 0.972 & 1.996 \\
\hline & $P$ & 0.386 & 0.148 \\
\hline \multirow{3}{*}{ Wheat group } & Variety & & \\
\hline & $F_{2,25}$ & 0.042 & 0.088 \\
\hline & $P$ & 0.959 & 0.916 \\
\hline
\end{tabular}

Table 3. Results of the Chemical Composition Analyses for the Twelve Varieties Together; Regression Analysis between C:N Ratio, Lignin, Cellulose or Hemicellulose and Weight Change and Consumption, respectively

\begin{tabular}{|c|c|c|c|c|}
\hline & C:N Ratio & Lignin & Cellulose & Hemicellulose \\
\hline \hline Weight change & & & & \\
\hline$F_{1,10}$ & 0.930 & 0.594 & 0.360 & 0.938 \\
\hline$P$ & 0.358 & 0.459 & 0.562 & 0.356 \\
\hline Consumption & & & & \\
\hline$F_{1,10}$ & 0.016 & 0.003 & 0.03 & 0.179 \\
\hline$P$ & 0.903 & 0.955 & 0.959 & 0.681 \\
\hline
\end{tabular}

Table 4. Mean Values $(n=4)$ of Cellulose, Hemicellulose, Lignin and $\mathrm{C} / \mathrm{N}$ Ratio for Leaves of the 18 Crop Varieties as well as the Pooled Transgenic Crops (GE) and the Pooled Non-Transgenic Crops (nonGE) (from Lindfeld et al. 2010)

\begin{tabular}{|c|c|c|c|c|}
\hline Variety & $\begin{array}{c}\text { Cellulose } \\
{[\% \text { DW] }}\end{array}$ & $\begin{array}{c}\text { Hemicellulose } \\
{[\% \text { DW] }}\end{array}$ & $\begin{array}{c}\text { Lignin } \\
{[\% \text { DW] }}\end{array}$ & $\begin{array}{c}\text { C/N } \\
\text { ratio }\end{array}$ \\
\hline \hline Pm3b\#1 & 33.87 & 29.95 & 6.81 & 35.01 \\
\hline Sb\#1 & 34.00 & 30.31 & 7.71 & 26.86 \\
\hline Pm3b\#2 & 32.04 & 31.63 & 8.06 & 27.31 \\
\hline Sb\#2 & 33.47 & 30.35 & 7.09 & 30.81 \\
\hline A9-Frisal & 34.34 & 30.13 & 6.55 & 34.50 \\
\hline A13-Frisal & 34.09 & 31.28 & 5.82 & 35.39 \\
\hline Frisal & 32.41 & 33.41 & 7.39 & 29.73 \\
\hline Toronit & 34.94 & 29.60 & 6.84 & 31.06 \\
\hline Rubli & 32.67 & 31.21 & 7.73 & 29.30 \\
\hline Bobwhite & 33.63 & 30.76 & 6.94 & 34.74 \\
\hline Estana & 37.24 & 31.34 & 5.35 & 33.08 \\
\hline Trado & 36.35 & 31.18 & 5.68 & 37.42 \\
\hline Mean GE & 33.07 & 30.95 & 7.43 & 31.04 \\
\hline Mean non-GE & 34.03 & 30.62 & 6.90 & 32.61 \\
\hline
\end{tabular}

\section{DISCUSSION}

We analysed the consumption of the leaf litter to estimate if decomposition, as essential ecosystem service, is negatively affected due to detrimental effects on earthworms' performance or feeding activity. Altered consumption behaviour would possibly lead to a changed nutrient cycle, since earthworms are a key soil species and greatly affect biological, physical and chemical soil properties and processes (Brown et al., 2004). We could not find significant differences in the consumption of GE and non-GE wheat in this experiment. Though some GE wheat varieties were consumed less than their isolines, no general trend of less 
consumption could be detected. This observation might hint, together with the slightly, not statistically significant, better performance of L. terrestris when feeding on GE wheat, to a feeding activity more triggered by the nutritional value of the crop varieties. Earthworms might adapt the amount of consumption to the quality of food as a pre-ingestive compensatory mechanism (Lavy et al., 2001). However, a chemical analysis of the structural plant components (Lindfeld et al. 2010) did not find significant differences between GE wheat and non-GE wheat and the regression analysis showed no correlation between structural plant components or $\mathrm{C} / \mathrm{N}$ ratio and the amount of litter consumption, respectively weight change of $L$. terrestris. The insertions of the transgenes do not seem to affect plant metabolism concerning the structural plant components we analysed and have no effect on the performance of $L$. terrestris. However, there are more factors important for nutritional value, palatability and decomposability. Fore example, soluble sugars or plant secondary compounds were not analysed in our experiment, but might explain differences in consumption and weight change.

Another explanation for differences in consumption and weight change of $L$. terrestris might be detected in the microbial colonisation of plant matter and soil. There are symbiotic interactions between earthworms and microorganisms and especially fungi are an important food resource for earthworms (Edwards and Fletcher, 1988). Microbial colonisation possibly increases leaf litter consumption because this provides earthworms with additional soluble $\mathrm{C}$ sources derived from microbial metabolism (Brown and Doube, 2004). It is possible that the different wheat varieties were colonised by different microorganisms or to an extent, which was more or less beneficial for individuals of $L$. terrestris and, thus, affecting their performance. However, there seems to be no general avoidance of GE wheat due to negative effects of the transgene products since $L$. terrestris performed in our experiment best on the four GE wheat varieties though Pm3b1, Pm3b2 and A9 were consumed least.

The overall low mortality of $4.2 \%$ during the experiment supports this assumption, in which only 1 of 5 dead individuals fed on GE wheat. We did not find significant differences in mortality between earthworms feeding on GE wheat or non-GE wheat. A comparison with other studies about effects of GE wheat on mortality of earthworms is not possible since there are no studies so far. However, there are several laboratory experiments analysing effects of $\mathrm{Bt}$ maize or Bt cotton on annelids. Our results are in accordance with those of Saxena and Stotzky (2001b), Hönemann et al. (2009) and Liu et al. (2009). None of them found a significantly higher mortality when feeding on Bt maize compared to non-Bt maize, respectively $\mathrm{Bt}$ cotton and non-Bt cotton.

Because earthworms are resistant animals, records of their survival alone may not give a true measure of the toxicity of pesticides or other toxins (Atlavinyté et al., 1982). We additionally measured and compared the weight change of the lumbricids in the course of the experiment to assess sublethal effects of GE wheat. We did not find any negative effects on earthworm weight change when feeding on GE wheat. In fact, individuals feeding on Pm3bl even gained weight. The overall poor performance of $L$. terrestris, however, may suggest that individuals were stressed irres- pective of the treatments, likely due to the low nutritional value of all offered food resources since litter is well-known as low-nutrient food (Nentwig et al. 2009). Consequently, differences found among different crop varieties were quite small with at most $10 \%$ and not significant. Taking into consideration that the gut content of $L$. terrestris makes up to $13 \%$ of the overall weight (Fründ et al., 2010) and that we did not check the gut content before or after the experiment, we can not exclude differences to be caused by that.

We can not confirm our risk formulation in terms of an ERA. Reasoned from our experiment there are no direct lethal or sublethal effects on the soil key species $L$. terrestris when feeding on senescent leaf material of GE wheat and there was no changed feeding behaviour detectable.

This study was conducted in a laboratory setting with only a few indicators (consumption, growth, mortality) that might respond to detrimental effects. It provides useful information about effects of GE wheat under a worst-case scenario in the laboratory, since our earthworms depended on only one food resource. Even under such conditions the results of our experiment give no evidence for detrimental effects on mortality or litter consumption. In the field exposure and dependence on GE wheat as food resource would be less than in the laboratory since in the field a mixture of different diets is available for earthworms and many other soil organisms support decomposition and nutrient cycling.

However, based on our experiment there are no predictions possible about potential long-term effects, which was not our aim since we focused on direct effects. Extended studies of more than one year are necessary to assess potential long-term effects of GE wheat on L. terrestris. In addition, we recommend that further life history traits and fitness parameter should be investigated, e.g. reproduction, cocoon production, development time, survival of offspring or food conversion efficiency. These are important parameter for earthworm community structure and might give useful information about potential long-term effects and conesquences for ecosystem functioning. For information about potential effects under natural conditions field experiment would be useful before further conclusions about ecological risks can be made.

Furthermore interactions with microorganisms should be taken into consideration, e.g. experimental setups in the laboratory with wheat varieties inoculated with specific microorganisms and without or a comparison of microbial growth on GE wheat and non-GE wheat. The nutritional value of the given food resource is a crucial factor for earthworm consumption and microorganisms can have a considerable impact on that (Edwards and Fletcher, 1988). To make such experiments more robust against stochasticity an increase of the sample size per variety and a higher age and weight standardisation of the worms is recommended.

Generally we want to emphasise how important it is to include not only GE plant varieties and their corresponding isolines into risk assessment studies, but also several additional conventional varieties as well as other crops. This allows to estimate naturally occurring variance in the gene pool of a given plant species as well as among different plant species and to evaluate the relevance of potential differences between GE and non-GE plants for ecosystem functioning. 


\section{ACKNOWLEDGEMENTS}

We thank Eva Knop and Florian Menzel for their support in statistical analyses and the reviewers for helpful remarks. This study is part of the National Research Programme NRP 59 "Benefits and risks of the deliberate release of genetically modified plants" (www.nrp59.ch) and we thank the Swiss National Science Foundation for funding.

\section{REFERENCES}

Atlavinyté, O, Galvelis, A, Daciulyté, J, Lugauskas, A (1982) Effects of entobacterin on earthworm activity. Pedobiologia, 23, 372-9.

Bent, AF, Mackey, D (2007) Elicitors, effectors, and r genes: The new paradigm and a lifetime supply of questions. Annual Review Phytopathology, 45, 399-436.

Bieri, S, Potrykus, I, Fütterer, J (2003) Effects of combinded expression of antifungal barley seed proteins in transgenic wheat on powdery mildew infection. Molecular Breeding, 11, 37-48.

Bliffeld, M, Mundy, J, Potrykus, I, Fütterer, J (1999) Genetic engineering of wheat for increased resistance to powdery mildew disease. Theoretical and Applied Genetics, 98, 1079-86.

Brown, GB, Doube, BM (2004) Functional interactions between earthworms, microorganisms, organic matter, and plants. In: Edwards, CA (ed.) Earthworm Ecology, CRC Press, Boca Raton, 213-39.

Brown, GB, Edwards, CA, Brussaard, L, (2004) How earthworms affect plant growth: burrowing into the mechanisms. In: Edwards, C.A. (ed) Earthworm ecology, CRC Press, Boca Raton, 13-49.

Brussaard, L, Behan-Pelletier, VM, Bignell, DE, Brown, VK, Didden, W, Folgarait, P, Fragoso, C, Freckman, DW, Gupta, VVSR, Hattori, T, Hawksworth, DL, Klopatek, C, Lavelle, P, Malloch, DW, Rusek, J, Soderstrom, B, Tiedje, JM, Virginia, RA (1997) Biodiversity and ecosystem functioning in soil. $A M B I O, 26,563-70$.

Brussaard, L, (1998) Soil fauna, guilds, functional groups and ecosystem processes. Applied Soil Ecology, 9, 123-35.

Dunger, W, Fiedler, HJ (1997) Methoden der Bodenbiologie, 2nd ed,Gustav Fischer, Jena.

Edwards, CA, Fletcher, KE (1988) Interactions between earthworms and microorganisms in organic-matter breakdown. Agriculture, Ecosystems \& Environment, 24, 235-47.

EFSA Panel on Genetically Modified Organisms (GMO) (2010) Guidance on the environmental risk assessment of genetically modified plants. EFSA Journal doi:10.2903/j.efsa.2010.1879.

Fernie, AR, Tadmor, Y, Zamir, D (2006) Natural genetic variation improving crop quality. Current Opinion in Plant Biology, 9, 196202.

Ferreira, RB, Monteiro, S, Freitas, R, Santos, CN, Chen, Z, Batista, LM, Duarte, J, Borges, A, Teixeira, AR (2007) The role of plant defence proteins in fungal pathogenesis. Molecular Plant Pathology, 8, $677-700$

Fründ, HC, Butt, K, Capowiez, Y, Eisenhauer, N, Emmerling, C, Ernst, G, Potthoff, M, Schaedler, M, Schrader, S (2010) Using earthworms as model organisms in the laboratory: Recommendations for experimental implementations. Pedobiologia, 53, 119-25.

Hönemann, L, Nentwig, W (2009) Are survival and reproduction of Enchytraeus albidus (Annelida: Enchytraeidae) at risk by feeding on BT-maize litter? European Journal of Soil Biology, 45, 351-5.

Ioset, JR, Urbaniak, B, Ndjoko-Ioset, K, Wirth, J, Martin, F, Gruissem, W, Hostettmann, K, Sautter, C (2007) Flavonoid profiling among wild type and related GM wheat varieties. Plant Molecular Biology, 65, 645-54.

James, C (2009) Global status of commercialized biotech/GM crops: The first fourteen years, 1996 to 2009. ISAAA Brief No. 41, ISAAA, Ithaca, NY.

Jouquet, P, Dauber, J, Lagerlof, J, Lavelle, P, Lepage, M (2006) Soil invertebrates as ecosystem engineers: intended and accidental effects on soil and feedback loops. Applied Soil Ecology, 32, 15364.

Knecht, S, Nentwig, W (2010) Effect of Bt maize on the reproduction and development of saprophagous Diptera over multiple generations. Basic and Applied Ecology, 11, 346-53.
Kotilainen, T, Setälä, H, Alatalo, I, Vuorisalo, T, Saloniemi, I (2004) Impacts of chitinase-transformed silver birch on leaf decomposition and soil organisms. European Journal of Soil Biology, 40, 155-161.

Kulikov, AM, 2005. Genetically modified organisms and risks of their introduction. Russian Journal of Plant Physiology, 52, 99-111.

Lavelle, P, Decaëns, T, Aubert, M, Barot, S, Blouin, M, Bureau, F, Margerie, P, Mora, P, Rossi, JP (2006) Soil invertebrates and ecosystem services. European Journal of Soil Biology, 42, S3-S14.

Lavy, D, Rijn van, MJ., Zoomer, HR., Verhoef, HA (2001) Dietary effects on growth, reproduction, body composition and stress resistance in the terrestrial isopods Oniscus asellus and Porcellio scaber. Physiological Entomology, 26, 18-25.

Lee, KE (1985) Earthworms. Their ecology and relationships with soils and land use. Academic Press, Sydney.

Lindfeld, A, Lang, C, Knop, E, Nentwig, W (2011) Hard to digest or a piece of cake? Does GM wheat affect survival and reproduction of Enchytraeus albidus (Annelida: Enchytraeidae)? Applied Soil Ecology, 47, 51-8.

Liu, B, Wang, L, Zeng, Q, Meng, J, Hu, WJ, Li, XG, Zhou, KX, Xue, K, Liu, DD, Zheng, YP (2009) Assessing effects of transgenic Cry1Ac cotton on the earthworm Eisenia fetida. Soil Biology \& Biochemistry, 41, 1841-6.

Moore, JC, Walter, DE, Hunt, HW (1988) Arthropod regulation of microbiota and mesobiota in belowground detrital food webs. Annual Review of Entomology, 33, 419-39.

Mulder, C, Lotz, LAP (2009) Biotechnology, environmental forcing, and unitended trophic cascades. Arthropod-Plant Interactions, 3, 131-9.

Nentwig, W, Bacher, S, Brandl, R (2009) Ökologie kompakt, 3rd ed, Springer, Heidelberg.

Peter, M, Lindfeld, A, Nentwig, W (2010) Does GM wheat affect saprophagous Diptera species (Drosophilidae, Phoridae)? Pedobiologia, 53, 271-279.

Poerschmann, J, Gathmann, A, Augustin, J, Langer, U, Górecki, T (2005) Molecular composition of leaves and stems of genetically modified $\mathrm{Bt}$ and near isogenic non-Bt maize - characterization of lignin patterns. Journal of Environmental Quality, 34, 1508-18.

R Development Core Team (2009) R: A language and environment for statistical computing. $R$ Foundation for Statistical Computing, Vienna, Austria. ISBN 3-900051-07-0, URL http:/www.Rproject.org).

Romeis, J, Battini, M, Bigler, F (2003) Transgenic wheat with enhanced fungal resistance causes no effects on Folsomia candida (Collembola: Isotomidae). Pedobiologia, 47, 141-7.

Ruppert, EE, Fox, RS, Barnes, RD (2004) Invertebrate Zoology, 6th ed, Brooks/Cole Publishing Company, Pacific Grove.

Sanvido, O, Romeis, J, Bigler, F (2007) Ecological impacts of genetically modified crops: ten years of field research and commercial cultivation. Advances in Biochemical Engineering Biotechnology, 107, 235-78.

Saxena, D, Stotzky, G (2001a) Bt corn has a higher lignin content than nonBt corn. American Journal of Botany, 88, 1704-6.

Saxena, D, Stotzky, G (2001b) Bacillus thuringiensis (Bt) toxin released from root exudates and biomass of Bt corn has no apparent effect on earthworms nematodes, protozoa, bacteria and fungi in soil. Soil Biology \& Biochemistry, 33, 1225-30.

Scheu, S (2003) Effects of earthworms on plant growth: patterns and perspectives. Pedobiologia, 47, 846-856.

Srichumpa, P, Brunner, S, Keller, B, Yahiaoui, N (2005) Allelic series of four powdery mildew resistance genes at the Pm3 locus in hexaploid bread wheat. Plant Physiology, 139, 885-95.

Sundaresha, S, Kumar, AM, Rohini, S, Math, SA, Keshamma, E, Chandrashekar, SC, Udayakumar, M (2010) Enhanced protection against two major fungal pathogens of groundnut, Cercospora arachidicola and Aspergillus flavus in transgenic groundnut overexpressing a tobacco beta 1-3 glucanase. European Journal of Plant Pathology, 126, 497-508.

Tan, F, Wang, J, Feng, Y, Chi, G, Kong, H, Qiu, H, Wei, S (2010) Bt corn plants and their straw have no apparent impact on soil microbial communities. Plant and Soil, 329, 349-364.

Whalen, JK, Sampedro, L (2009) Soil Ecology and Management, CABI, Wallingford.

Wardle, DA (2002) Communities and ecosystems: linking the aboveground and belowground components, Princeton University Press, Princeton.

Yahiaoui, N, Srichumpa, P, Dudler, R, Keller, B (2004) Genome analysis at different ploidy levels allows cloning of the powdery mildew 
resistance gene Pm3b from hexaploid wheat. The Plant Journal, 37, 528-38.

Zeilinger, AR, Andow, DA, Zwahlen, C, Stotzky, G (2010) Earthworm populations in a northern US Cornbelt soil are not affected by long- term cultivation of $\mathrm{Bt}$ maize expressing Cry $1 \mathrm{Ab}$ and $\mathrm{Cry} 3 \mathrm{Bb} 1$ proteins. Soil Biology \& Biochemistry 42, 1284-92.

Zwahlen, C, Hilbeck, A, Howald, R, Nentwig, W (2003) Effects of transgenic Bt corn litter on the earthworm Lumbricus terrestris. Molecular Ecology, 12, 1077-86

(C) Lindfeld and Nentwig; Licensee Bentham Open.

This is an open access article licensed under the terms of the Creative Commons Attribution Non-Commercial License (http://creativecommons.org/ licenses/by-nc/3.0/), which permits unrestricted, non-commercial use, distribution and reproduction in any medium, provided the work is properly cited. 